\title{
Monoclonal autoantibodies specific for oxidized phospholipids or oxidized phospholipid-protein adducts inhibit macrophage uptake of oxidized low-density lipoproteins
}

\author{
Sohvi Hörkkö, ${ }^{1}$ David A. Bird, ${ }^{1}$ Elizabeth Miller, ${ }^{1}$ Hiroyuki Itabe, ${ }^{2}$ Norbert Leitinger, ${ }^{3}$ \\ Ganesamoorthy Subbanagounder, ${ }^{3}$ Judith A. Berliner, ${ }^{3}$ Peter Friedman, ${ }^{4}$ \\ Edward A. Dennis, ${ }^{4}$ Linda K. Curtiss, ${ }^{5}$ Wulf Palinski, ${ }^{1}$ and Joseph L. Witztum ${ }^{1}$
}

\footnotetext{
${ }^{1}$ Department of Medicine, University of California, San Diego, La Jolla, California 92093-0682, USA

${ }^{2}$ Department of Microbiology and Molecular Pathology, Faculty of Pharmaceutical Sciences, Teikyo University, 1091-1 Sagamiko, Kanagawa 199-0195, Japan

${ }^{3}$ Department of Medicine, University of California, Los Angeles, Los Angeles, California, 90024-1732, USA

${ }^{4}$ Department of Chemistry and Biochemistry, University of California, San Diego, La Jolla, California 92093-0682, USA

${ }^{5}$ Departments of Immunology and Vascular Biology, The Scripps Research Institute, La Jolla, California 92037, USA
}

Address correspondence to: Joseph L. Witztum, or Sohvi Hörkkö, Department of Medicine, University of California, San Diego, 9500 Gilman Drive, La Jolla, California 92093-0682, USA. Phone: (619) 534-4347; Fax: (619) 534-2005;

E-mail: jwitztum@ucsd.edu; shorkko@ucsd.edu

Received for publication July 9, 1998, and accepted in revised form November 19, 1998.

\begin{abstract}
We recently cloned monoclonal IgM autoantibodies which bind to epitopes of oxidized low-density lipoprotein (OxLDL) from apoE-deficient mice ( $\mathrm{EO}^{-}$autoantibodies). We now demonstrate that those $\mathrm{EO}^{-}$ autoantibodies that were originally selected for binding to copper-oxidized low-density lipoproteins (CuOx-LDL), also bound both to the oxidized protein and to the oxidized lipid moieties of CuOx-LDL. The same $\mathrm{EO}^{-}$autoantibodies showed specific binding to products of oxidized 1-palmi-toyl-2-arachidonoyl-phosphatidylcholine (OxPAPC) and to the specific oxidized phospholipid, 1-palmitoyl-2-(5-oxovaleroyl)-phosphatidyl-choline (POVPC), whereas oxidation of fatty acids (linoleic or arachidonic acid) or cholesteryl esters (cholesteryl-oleate or cholesteryl-linoleate) did not yield any binding activity. Those $\mathrm{EO}^{-}$autoantibodies that bound to oxidized phospholipids (e.g., EO6) inhibited the binding and degradation of $\mathrm{CuOx}-\mathrm{LDL}$ by mouse peritoneal macrophages up to $91 \%$, whereas other IgM EO- autoantibodies, selected for binding to malondialdehyde (MDA)-LDL, had no influence on binding of either $\mathrm{CuOx}-\mathrm{LDL}$ or MDA-LDL by macrophages. $\mathrm{F}\left(\mathrm{ab}^{\prime}\right)_{2}$ fragments of $\mathrm{EO} 6$ were equally effective as the intact EO6 in preventing the binding of CuOx-LDL by macrophages. The molar ratios of IgM to LDL needed to maximally inhibit the binding varied from $\sim 8$ to 25 with different CuOx-LDL preparations. Finally, a POVPC-bovine serum albumin (BSA) adduct also inhibited CuOx-LDL uptake by macrophages. These data suggest that oxidized phospholipid epitopes, present either as lipids or as lipid-protein adducts, represent one class of ligands involved in the recognition of OxLDL by macrophages, and that apoE-deficient mice have IgM autoantibodies that can bind to these neoepitopes and inhibit OxLDL uptake.
\end{abstract}

J. Clin. Invest. 103:117-128 (1999).

\section{Introduction}

Oxidation of low-density lipoproteins (LDL) plays an important role in atherogenesis. Oxidized LDL (OxLDL) (and certain chemically modified LDL) have the ability to bind to scavenger receptors, which can lead to unregulated accumulation of cholesterol in macrophages and formation of foam cells. Consequently, it has been proposed that OxLDL is one of the physiological ligands for the scavenger receptors. Numerous studies have supplied evidence that $\mathrm{OxLDL}$ is present in vivo. For example, OxLDL can be extracted from atherosclerotic lesions (1-3), epitopes of OxLDL can be demonstrated immunohistochemically in atherosclerotic lesions in humans and animal models (1,4-8), autoantibodies reactive with OxLDL are present in plasma and lesions of humans and animals $(1,8-10)$, and small amounts of minimally oxidized LDL can be demonstrated in plasma (10-14).
Although OxLDL causes lipid deposition in macrophages, it may also have other characteristics that affect atherogenesis. For example, OxLDL is chemotactic for monocytes (15) and for T cells (16), and cytotoxic for cultured endothelial cells (17). Also, studies have shown that minimally oxidized LDL (mm-LDL) stimulates the release of macrophage colony-stimulating factor (M-CSF) (18) and monocyte chemoattractant protein-1 (MCP-1) (19) from endothelial cells, which recruits monocytes into the arterial wall and facilitates their differentiation into tissue macrophages.

Although many of the proatherogenic properties of OxLDL are known, little is known of the structures in OxLDL that cause these effects. LDL oxidation is a very complex process and much heterogeneity is generated during this process. During oxidation both the protein and the lipid moieties of LDL particles can be modified. A major 


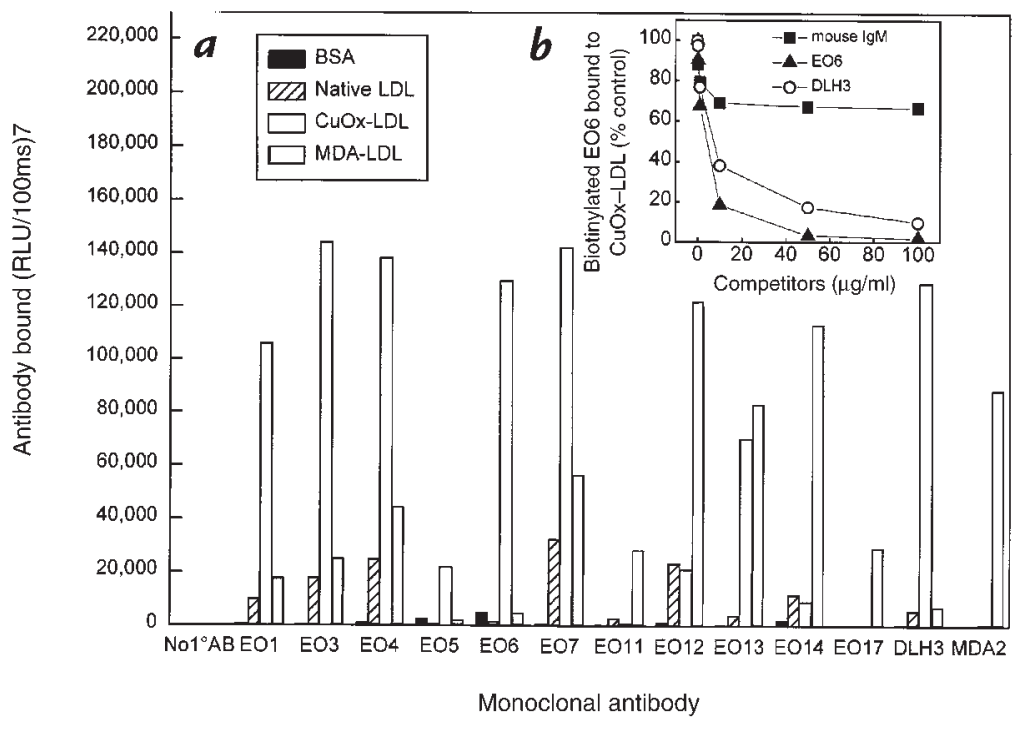

Figure 1

(a) Immunoassay showing binding of natural monoclonal autoantibodies from apoE-deficient mice (EO1-EO17), a murine MAB from mice immunized with homogenates of human atheromatous plaque (DLH3) and MDA2 (a murine MAB to MDA-lysine), to BSA, native $\mathrm{LDL}, \mathrm{LDL}$ oxidized with copper for $16 \mathrm{~h}(\mathrm{CuOx}$ $L D L)$, and MDA-modified LDL (MDA-LDL). The antigens were plated at $10 \mu \mathrm{g} / \mathrm{ml}$ overnight $\left(4^{\circ} \mathrm{C}\right)$, and the purified antibodies were incubated with antigen at $10 \mu \mathrm{g} / \mathrm{ml}$ for $1 \mathrm{~h}$ (room temperature). The amount of antibody bound was then measured with alkaline phosphatase-labeled goat anti-mouse IgM (or anti-lgG for MDA2) antibody using chemiluminescent technique. Each bar is the mean of triplicate determinations. ( $\boldsymbol{b}$ ) Competition immunoassay showing binding of a fixed and limiting dilution of biotinylated EO6 MAB to immobilized $\mathrm{CuOx}$-LDL in the presence of increasing amounts of nonimmune mouse $\operatorname{lgM}, \mathrm{EO}$, and MAB DLH3. LDL, low-density lipoproteins; $M A B$, monoclonal antibody; $M D A$, malondialdehyde; $R L U$, relative light units. process is the peroxidation of the polyunsaturated fatty acids (PUFA) present in phospholipids and cholesteryl esters. A variety of highly reactive breakdown products are generated as a result, such as malondialdehyde (MDA) or 4-hydroxynonenal (4-HNE) (20). In turn, these aldehydes can form Schiff-base adducts with lysine residues of the intimately associated apoprotein of LDL, apoB. Aldehyde groups on the modified fatty acid fragments, still attached to the phospholipid backbone, could also form such adducts, leading to modified lipid-protein adducts or lipid-lipid adducts (Fig. 1, and in ref. 21). In addition, during LDL oxidation apoB breaks down as a result of direct oxidative attack, to yield a mixture of fragments of different sizes (from 14 to over $550 \mathrm{kDa}$ ) (22). Thus, as a result of oxidation, literally hundreds of different structures are generated that could be immunogenic. We have termed such epitopes "oxidation-specific epitopes" $(1,23)$.

Previously, Parthasarthy et al. (24) demonstrated that the delipidated protein moiety of OxLDL could bind to macrophage scavenger receptors and inhibit the binding of intact OxLDL. Recently, Terpstra et al. (25) used competition studies to demonstrate that microemulsions made from lipids extracted from OxLDL could also inhibit the uptake and degradation of intact OxLDL. The purpose of the present study was to characterize some of the ligands on OxLDL that are responsible for the uptake of OxLDL by macrophage scavenger receptors. We used previously generated natural monoclonal autoantibodies to epitopes of oxidized lipoproteins cloned from apoE-deficient mice (10) and a monoclonal antibody (MAB) generated using human atheromatous plaque as immunogen (26). We provide evidence that specific oxidized phospholipids in OxLDL, present as lipids or as lipid-protein adducts, could be ligands for macrophage recognition.

\section{Methods}

Materials. L- $\alpha 1$-palmitoyl-2-arachidonoyl-sn-glycero-3-phosphocholine (PAPC) was obtained from Avanti Polar Lipids (Alabaster, Alabama, USA). 1-palmitoyl-2-(5-oxovaleroyl)-sn-glycero-3-phosphocholine (POVPC) was synthesized by H. Itabe (Teikyo University) as described (27) and by the laboratory of J.A. Berliner
(University of California, Los Angeles) (28). Alkaline phosphatase-labeled goat anti-mouse IgM (and anti-IgG) were from Sigma Chemical Co. (St. Louis, Missouri, USA), and LumiPhos 530 was from Lumigen Inc. (Southfield, Michigan, USA).

Monoclonal antibodies. "Natural" MABs directed against oxidation-specific epitopes of OxLDL were cloned from hybridomas generated from apoE-deficient mice that had not been immunized exogenously, as described in detail previously (10). B lymphocytes from the spleens of two apoE-deficient mice were fused with a myeloma cell line. Hybridoma supernatants were screened for binding to OxLDL or to models of OxLDL epitopes: MDA-LDL and a mixture of 4- and 16-h copper-oxidized LDL (CuOx-LDL). Selected hybridomas were cloned by limiting dilution, and cells were injected intraperitoneally into Pristane (Aldrich Chemical Co., Milwaukee, Wisconsin, USA) primed BALB/C mice to produce ascites fluid. After cloning, all $13 \mathrm{MABs}$, termed $\mathrm{EO}^{-}$autoantibodies, were isotyped as IgM and characterized as described (10). All the EO antibodies used in these experiments were purified from ascites by fast protein liquid chromatography (FPLC) as described previously (10). In addition, we used an IgG1a MAB termed MDA2 (23), which is specific for MDA-lysine epitopes, and murine MAB MB47, which is specific for LDL apoB (29). The MAB DLH3 was generated by Itabe and colleagues by immunizing mice with homogenates of human atheromatous plaque (26). DLH3 is an IgM MAB selected for its ability to bind to CuOx-LDL.

Chemiluminescent immunoassay for antibody binding. Antigens in PBS (containing $0.27 \mathrm{mM}$ EDTA) were plated into 96-well, white, round-bottomed High Binding Microfluor microtitration plates (Dynex Technologies, Chantilly, Virginia, USA) overnight at $4^{\circ} \mathrm{C}$. The wells were washed four times with PBS and blocked with PBS containing $1 \%$ BSA (BSA-PBS) for $30 \mathrm{~min}$. Antibodies were diluted with BSA-PBS and incubated for $1 \mathrm{~h}$ at room temperature. The amount of primary antibody bound was measured with alkaline phosphatase-labeled goat anti-mouse IgM (or anti-IgG) (Sigma Chemical Co.) (in a TBS buffer containing $150 \mathrm{mM} \mathrm{NaCl}, 50 \mathrm{mM}$ Tris base, $0.27 \mathrm{mM}$ EDTA, and $1 \% \mathrm{BSA})$ using chemiluminescent technique $(21,30)$.

Competition immunoassays were performed by incubating 25 $\mu \mathrm{l}$ of increasing concentrations of competitors with $25 \mu \mathrm{l}$ of $\mathrm{MAB}(10 \mu \mathrm{g} / \mathrm{ml})$ at room temperature in antigen-coated wells for $1 \mathrm{~h}$. After four washes with PBS, the amount of antibody bound was measured with alkaline phosphatase-labeled goat anti-mouse IgM.

Preparation of copper-oxidized LDL and MDA-LDL. Copper oxidation and MDA modification of LDL were carried out as 


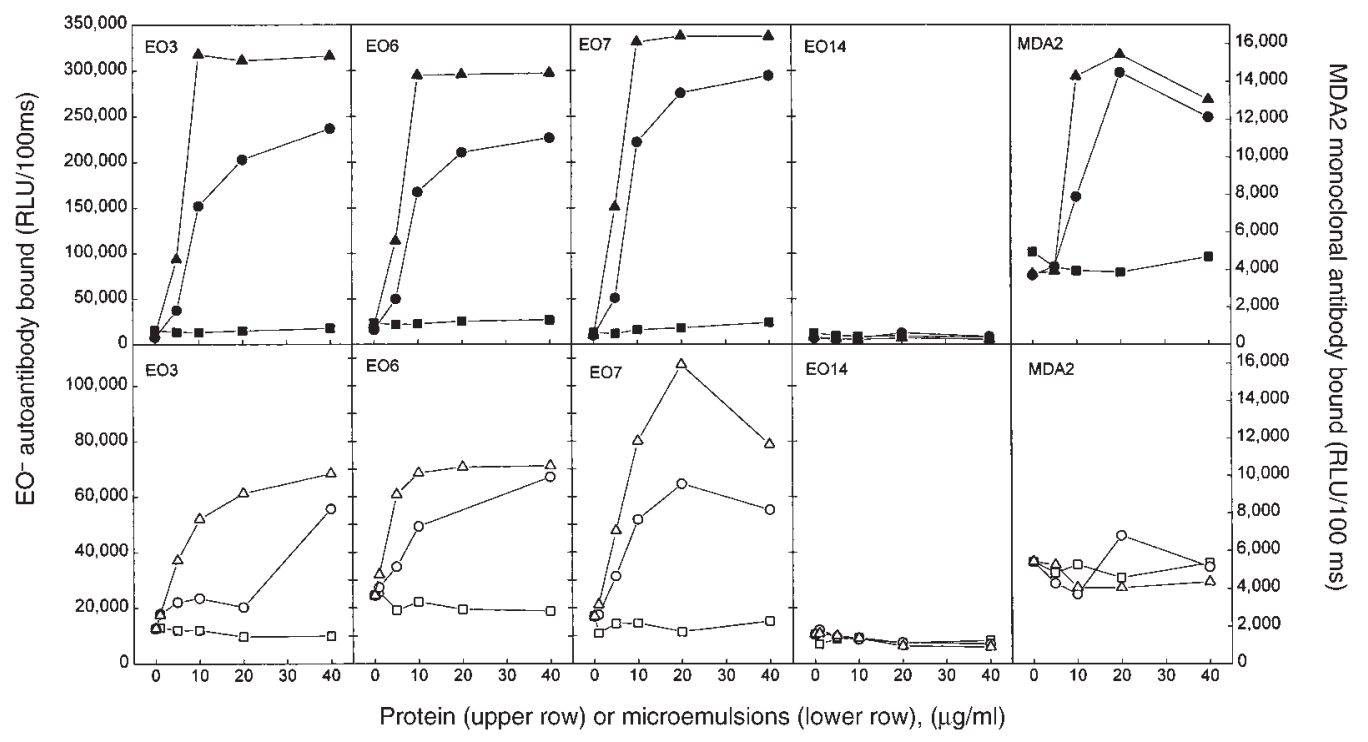

Figure 2

Immunoassay showing binding of MABs EO3, EO6, EO7, EO14, and MDA2 to the protein moiety (upper row) or to the lipid moiety (lower row) of native LDL (squares), LDL oxidized with copper for $4 \mathrm{~h}$ (circles), and LDL oxidized with copper for $18 \mathrm{~h}$ (triangles). Protein and lipid moieties of native and OxLDL preparations were separated with chloroform/methanol extraction, and the extracted lipids were made into microemulsions by extrusion. Then, $10 \mu \mathrm{g} / \mathrm{ml}$ of the MABs was incubated with antigens, and the amount of antibody bound was measured with alkaline phosphatase-labeled goat anti-mouse $\operatorname{lgM}$ (or IgG) secondary antibody. Each point is the mean of triplicate determinations.

described in detail previously (23).

LDL lipid extraction and microemulsion preparation. LDL lipids and protein were separated with chloroform/methanol extraction as described in detail previously (25). Then, $2 \mathrm{ml}$ of methanol and $2 \mathrm{ml}$ of chloroform were added to $1-2 \mathrm{mg}$ of LDL protein in $1.8 \mathrm{ml} \mathrm{PBS}$ containing $0.01 \mathrm{M} \mathrm{HCl}$. After vortexing, the mixture was centrifuged at $1,800 \mathrm{~g}$ for $10 \mathrm{~min}$, and the chloroform phase was removed and dried under $\mathrm{N}_{2}$. PBS was added to the dried lipids, vortexed until the lipids were in suspension, and then extruded 8-10 times through $0.1 \mu \mathrm{m}$ polycarbonate membranes under $\mathrm{N}_{2}$ flow. For flow cytometry experiments, the lipid microemulsions were labeled by adding 3,3'-dihexadecyloxacarbocyanine (DiO) (Molecular Probes Inc., Eugene, Oregon, USA) to the lipid extracts at a weight ratio of $1 \%$.

The chloroform/methanol- extracted $\mathrm{CuOx}$-LDL protein was washed two times with ice-cold $\mathrm{H}_{2} \mathrm{O}$, once with ice-cold acetone, and then once with ice-cold $\mathrm{H}_{2} \mathrm{O}$; it was then solubilized with octylglucoside (30 times the protein mass) as described previously (24). Octylglucoside was removed by extensive dialysis against PBS.

Preparation of oxidized PAPC. One to two milligrams of PAPC was dried on the surface of a 50-ml glass tube and exposed to air for 16-24 h. The oxidized PAPC (OxPAPC) was then solubilized in ethanol, and the fatty acids were analyzed in a Varian gas chromatograph (Varian, Walnut Creek, California, USA) equipped with a column of $10 \%$ Silar 5CP on 100/120 Gas Chrom QII (Alltech Associates Inc., Deerfield, Illinois, USA) as described (31).

Preparation of POVPC-modified BSA. POVPC (final $2 \mathrm{mM}$ ) was dried onto a glass tube and incubated with $1 \mathrm{mg} / \mathrm{ml}$ of BSA at $37^{\circ} \mathrm{C}$ for $4 \mathrm{~h}$. Then, $10 \mathrm{mM}$ of $\mathrm{NaCNBH}_{3}$ was added and the mixture was further incubated overnight at $37^{\circ} \mathrm{C}$. After incubation the unbound POVPC was removed by extensive dialysis with PBS.

Antibody absorption experiments. Increasing concentrations of native PAPC, OxPAPC, or microemulsions made from lipids extracted from native $\mathrm{LDL}$ or $\mathrm{CuOx}$-LDL were incubated with 1.0 $\mathrm{ml}$ of MABs $(10 \mu \mathrm{g} / \mathrm{ml})$ in PBS for $1 \mathrm{~h}$. The immunocomplexes were pelleted by spinning at $13,000 \mathrm{~g}$ (native PAPC and OxPAPC) or $100,000 \mathrm{~g}$ (microemulsions), and the supernatants were tested for remaining binding activity in the solid phase immunoassay. Macrophage binding and degradation assays. Mouse peritoneal macrophages were elicited by intraperitoneal injection of $2 \mathrm{ml}$ thioglycollate medium (Difco Laboratories, Detroit, Michigan, USA) three days before harvesting the cells. The macrophages were plated in 24-well clustered dishes at a density of $10^{6}$ cells/well in $0.5 \mathrm{ml}$ of Roswell Park Memorial Institute medium (RPMI)-1640 containing 5\% FCS. Nonadherent cells were removed after $3 \mathrm{~h}$ and the medium replaced for an overnight incubation. The degradation or binding of ${ }^{125} \mathrm{I}-\mathrm{CuOx}$-LDL or ${ }^{125}$ I-MDA-LDL by cells was determined using methods described by Goldstein et al. (32). For degradation, the indicated concentration of ${ }^{125} \mathrm{I}-\mathrm{CuOx}$-LDL or ${ }^{125} \mathrm{I}-\mathrm{MDA}$-LDL in serum-free media was added to each well in the absence or presence of competitors for $5 \mathrm{~h}$ at $37^{\circ} \mathrm{C}$. The amount of lipoprotein degraded was determined as the amount of ${ }^{125}$ I-labeled TCA-soluble (noniodide) material present in the medium. Cells were washed with PBS, solubilized in $0.2 \mathrm{M} \mathrm{NaOH}$, and aliquots were removed for counting as well as for protein determination by the method of Lowry et al, (33). To determine binding of ${ }^{125} \mathrm{I}-\mathrm{CuOx}$-LDL or ${ }^{125} \mathrm{I}-\mathrm{MDA}$ LDL, cells were preincubated at $4^{\circ} \mathrm{C}$ for $30 \mathrm{~min}$ in serum-free medium. Cells were kept on ice during the entire binding assay. After $3 \mathrm{~h}$, cells were washed with ice-cold 1\% BSA-PBS followed by three washes with PBS alone and finally solubilized in $0.2 \mathrm{M}$ $\mathrm{NaOH}$. Aliquots were removed for counting and protein determination. In some experiments cell association was determined at $37^{\circ} \mathrm{C}$ as described previously (32). In $4^{\circ} \mathrm{C}$ binding or $37^{\circ} \mathrm{C}$ cellassociation and degradation assays, the amount of lipoprotein bound or degraded per milligram of cell protein was calculated, and the results were expressed as the percentage of control in the absence of any competitor.

Flow cytometry analysis. Resident peritoneal macrophages were isolated from female Swiss-Webster mice by peritoneal lavage with PBS. The cells were plated in a 12 -well dish at a density of $1.3 \times 10^{6}$ cells/well in DMEM containing $10 \%$ FCS. After $3 \mathrm{~h}$, the cells were washed and fresh medium was added. The following day, the cells were incubated with DiO-labeled microemulsions (see above) for $2 \mathrm{~h}$ at $4^{\circ} \mathrm{C}$, washed, scraped 


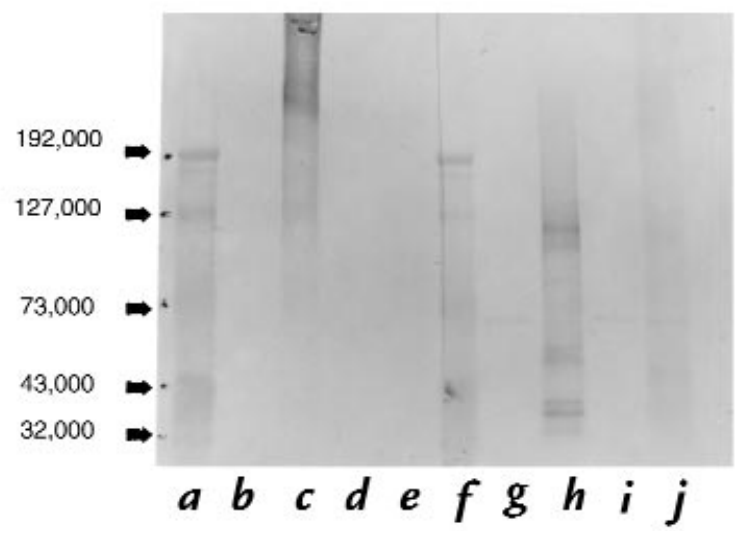

Figure 3

Western blot analysis of lipid and protein moieties of $\mathrm{CuOx}-\mathrm{LDL}$ and native LDL using MABs EO6 and MB47 (anti-apoB antibody) after SDSPAGE under reducing conditions. (a) Standards. (b) EO6 binding to lipids from CuOx-LDL. (c) EO6 binding to delipidated protein from CuOx-LDL. (d) EO6 binding to lipids from native -LDL. (e) EO6 binding to delipidated protein from native LDL. ( $f$ ) Standards. $(g)$ MB47 binding to lipids from native LDL. (h) MB47 binding to delipidated protein from native LDL. (i) MB47 binding to lipids from CuOx-LDL. (j) MB47 binding to delipidated protein from CuOx-LDL.

from the wells, and then resuspended in PBS containing 0.1\% BSA and $0.01 \% \mathrm{NaN}_{3}$. Mean fluorescence intensity was measured by flow cytometry (Becton- Dickinson Immunocytometry Systems, San Jose, California, USA)

Preparation of $\mathrm{F}\left(\mathrm{ab} \mathrm{b}^{\prime}\right)_{2}$ fragments. To prepare $\mathrm{F}\left(\mathrm{ab}^{\prime}\right)_{2}$ fragments, the IgM was dialyzed overnight at $4^{\circ} \mathrm{C}$ against $100 \mathrm{mM}$ sodium acetate, $150 \mathrm{mM} \mathrm{NaCl}$, and $0.05 \%$ sodium azide, $\mathrm{pH} 4.5$ (digestion buffer). A column containing $2 \mathrm{ml}$ immobilized pepsin (Pierce Chemical Co., Rockford, Illinois, USA) was equilibrated with digestion buffer. The IgM was applied to the column and incubated at $37^{\circ} \mathrm{C}$ for $1.5 \mathrm{~h}$. The fractionated IgM was eluted with $2 \mathrm{ml}$ of digestion buffer, and the $\mathrm{F}\left(\mathrm{ab}^{\prime}\right)_{2}$ was subsequently successively separated with spin concentrators with molecular weight cutoffs of 300,000 and 30,000 (MSI, Westboro, Massachusetts, USA). The final preparation was dialyzed extensively against PBS, pH 7.4. SDS-PAGE and silver staining of the digested IgM demonstrated a major band at $\sim 150 \mathrm{kDa}$, corresponding to the appropriate $\mathrm{F}\left(\mathrm{ab}^{\prime}\right)_{2}$ fragments. There was also a small band of $\sim 90 \mathrm{kDa}$, presumably corresponding to more extensively digested fragments.

Western blot. CuOx-LDL and native -LDL were electrophoresed on SDS 4\%-12\% Tris-glycine polyacrylamide gels using Novex precast gels and Xcell II Mini-Cell apparatus (Novex, San Diego, California, USA). Fresh $\beta$-mercaptoethanol ( $2.5 \%$ final concentration) was used to reduce the samples. Proteins were electrotransferred to nitrocellulose membranes, and transfer was confirmed with $0.1 \%$ Ponceau S solution (Sigma Chemical Co.) staining of the membrane. Membranes were blocked with Super Block (Pierce Chemical Co.) for $45 \mathrm{~min}$ and washed with TBS (0.05\% Tween-20). Primary antibodies (EO6 and biotinylated MB47) were diluted in 3\% BSA-TBS (0.01\% Tween-20) and incubated for $1 \mathrm{~h}$ at room temperature, and the membranes were washed five to seven times. The bound antibodies were detected with alkaline phosphatase-labeled goat anti-mouse IgM antibodies (EO6) or alkaline phosphatase-labeled avidin (biotinylated MB47) (Pierce Chemical Co.). Alkaline phosphatase was visualized with Alkaline Phosphatase Conjugate Substrate Kit (Bio-Rad Laboratories Inc., Hercules, California, USA)

\section{Results}

Antibody binding to OxLDL. We have shown previously that a panel of natural monoclonal autoantibodies cloned from apoE-deficient mice ( $\mathrm{EO}^{-}$autoantibodies) recognizes model epitopes of OxLDL (10). Figure $1 a$ shows the binding of selected $\mathrm{EO}^{-}$autoantibodies to $\mathrm{CuOx}$-LDL and MDA-LDL. In general, antibodies initially selected for predominant recognition of $\mathrm{CuOx}-\mathrm{LDL}$ (EO1 to EO7) had stronger binding to $\mathrm{CuOx}-\mathrm{LDL}$ than to MDALDL, and antibodies selected for recognition of MDALDL (EO11 to EO17) bound better to MDA-LDL (Fig. 1a). EO13 showed some degree of binding to both $\mathrm{CuOx}$ LDL and MDA-LDL. The specificity of MDA2, a mouse IgG MAB made against MDA-LDL (23), is shown for comparison (Fig. 1a). MDA2 frequently shows little binding to intact $\mathrm{CuOx}$-LDL, but as noted below, binds well to the delipidated apoprotein of CuOx-LDL.

MAB DLH3, generated by immunizing mice with homogenates of human atheromatous plaque (26), was shown previously to bind to foam cells in atherosclerotic lesions and to CuOx-LDL $(26,27)$. Because the binding properties of DLH3 in our assays were so similar to the binding properties of EO6, we tested the ability of DLH3 to compete with biotinylated EO6 for binding to CuOx-LDL. Fig. $1 b$ demonstrates that DLH3 competed for $>90 \%$ of the EO6 binding to $\mathrm{CuOx}$-LDL, suggesting that these two monoclonal antibodies are directed against a closely related or identical epitope.

Antibody binding to the protein or lipid moiety of OxLDL. During the oxidation of LDL a large number of reactive lipid peroxidation products are generated, which can modify the apoprotein as well as the lipids in LDL. To investigate whether the epitopes for the $\mathrm{EO}^{-}$autoanti-

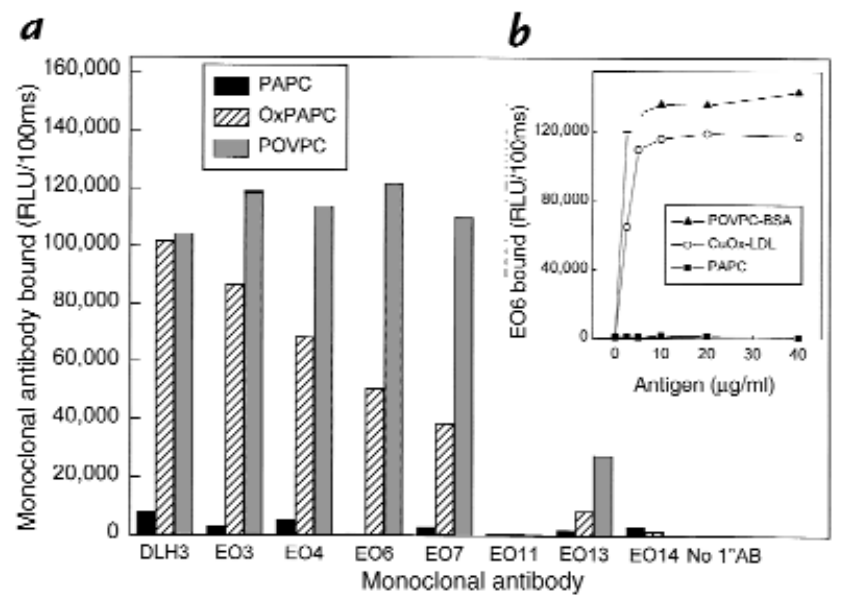

\section{Figure 4}

(a) Immunoassay showing binding of $\mathrm{EO}^{-}$autoantibodies and $\mathrm{DLH} 3$ to unoxidized PAPC liposomes, OxPAPC liposomes, or POVPC. The liposomes were plated at $10 \mu \mathrm{g} / \mathrm{ml}$ overnight $\left(4^{\circ} \mathrm{C}\right)$, and POVPC $(10 \mu \mathrm{g} / \mathrm{ml})$ was plated onto the microtiter wells by evaporation with air for $15 \mathrm{~min}$ just before use. Antibodies $(10 \mu \mathrm{g} / \mathrm{ml})$ were then incubated with antigens for $1 \mathrm{~h}$ (room temperature). The amount of antibody bound was measured with alkaline phosphatase-labeled goat anti-mouse IgM antibody using chemiluminescent technique. (b) Binding of EO6 to increasing concentrations of PAPC, CuOx-LDL, or POVPC-BSA. Each point is the mean of triplicate determinations. OxPAPC, oxidized PAPC; PAPC, unoxidized L- $\alpha 1$-palmitoyl-2-arachidonoyl-sn-glycero-3-phosphocholine; POVPC, 1 palmitoyl-2-(5-oxovaleroyl)-sn-glycero-3-phosphocholine. 


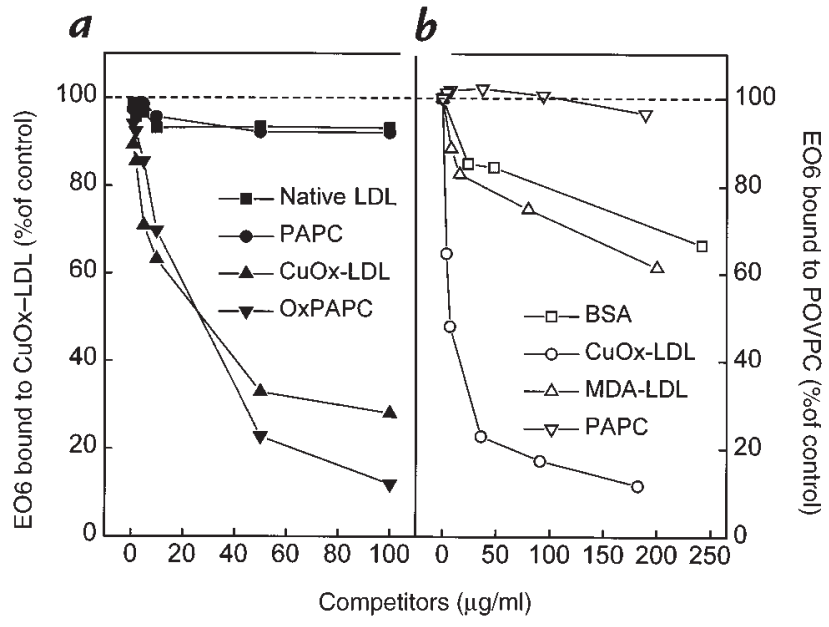

Figure 5

(a) Competition immunoassay showing binding of a limiting and constant amount of EO6 to $\mathrm{CuOx}$-LDL in the presence of increasing amounts of native LDL, CuOx-LDL, PAPC liposomes, and OxPAPC liposomes. Control incubations with EO6 without competitors were performed under identical conditions and the results are expressed as percentage of control. ( $\boldsymbol{b}$ ) Competition immunoassay showing binding of a fixed and limiting amount of EO6 to POVPC in the presence of increasing amounts of BSA, CuOx-LDL, MDA-LDL, and native unoxidized PAPC liposomes. Control incubations with EO6 without competitors were performed under identical conditions, and the results are expressed as percentage of control. Each point is the mean of triplicate determinations.

bodies are in the protein or in the lipid moiety of OxLDL, we separated the lipids and protein with chloroform/methanol extraction. The lipids extracted from the $\mathrm{CuOx}$-LDL were reconstituted into microemulsions by extrusion through a polycarbonate filter (see Methods). Figure 2 demonstrates the binding of selected $\mathrm{EO}^{-}$ autoantibodies to the immobilized delipidated protein moiety (upper row) or the immobilized lipid moiety (lower row) of CuOx-LDL. All the autoantibodies that specifically bound to the intact $\mathrm{CuOx}-\mathrm{LDL}$ (EO3, EO6, and EO7; Fig. 1) also bound both to the protein and to the lipid portion of CuOx-LDL. More binding was observed to the protein and lipid moieties of LDL oxidized with copper for 18 hours than to that oxidized for only four hours. No binding was observed to the protein or lipids extracted from native-LDL. EO14, which was selected for binding to MDA-LDL, did not bind to either lipid or protein fractions. The monoclonal IgG antibody to MDAlysine (MDA2) showed binding only to the $\mathrm{CuOx}$-LDL protein portion. While these experiments are representative, there was variation in binding to different OxLDL preparations, presumably reflecting different degrees of modification of these preparations.

In other experiments, we also demonstrated that the $\mathrm{EO}^{-}$autoantibodies bound to the lipids extracted from CuOx-LDL (but not from native LDL) even when the extracted lipids were solubilized in ethanol and directly coated onto microtiter wells (data not shown). This suggests that the MABs recognize the epitopes in the lipid moiety of $\mathrm{CuOx}-\mathrm{LDL}$ whether the extracted lipids are in a more organized form (microemulsions) or in an unorganized form (just as plated lipids on microtiter wells).
The amount of protein contamination in the lipid microemulsions prepared from $\mathrm{CuOx}$-LDL was estimated by acid hydrolysis followed by quantitative amino acid analysis using ion-exchange chromatography (25). For every $1 \mathrm{mg}$ of OxLDL protein extracted, $\sim 13 \mu \mathrm{g}$ of amino acids was measured in the lipid fraction (25). Thus, even at the maximum amount of lipid added to the microtiter well, there would be $\sim 26 \mathrm{ng}$ of protein added, of which $<10 \%$ binds; therefore, there would be $2.6 \mathrm{ng}$ protein bound to the lipid-coated well. Also, Western blots of the lipid fractions showed no staining with antibody MB47 (Fig. 3, lanes $g$ and $i$ ), which binds with high affinity to apoB (29) as well as to oxidized apoB fragments (23).

Antibody binding to OxLDL on a Western blot analysis. The data above demonstrate binding of the $\mathrm{EO}^{-}$autoantibodies to the protein moiety of $\mathrm{CuOx}$-LDL. To further test if the epitopes for the MABs were lipids covalently bound to the protein moiety of $\mathrm{CuOx}-\mathrm{LDL}$, we ran a sodium dodecyl sulfate-polyacrylamide gel electrophoresis (SDS-PAGE) of CuOx-LDL and native LDL under reducing conditions. The gel was electrotransferred to nitrocellulose and the binding of EO6 MAB was detected. Figure 3 shows that EO6 bound exten-

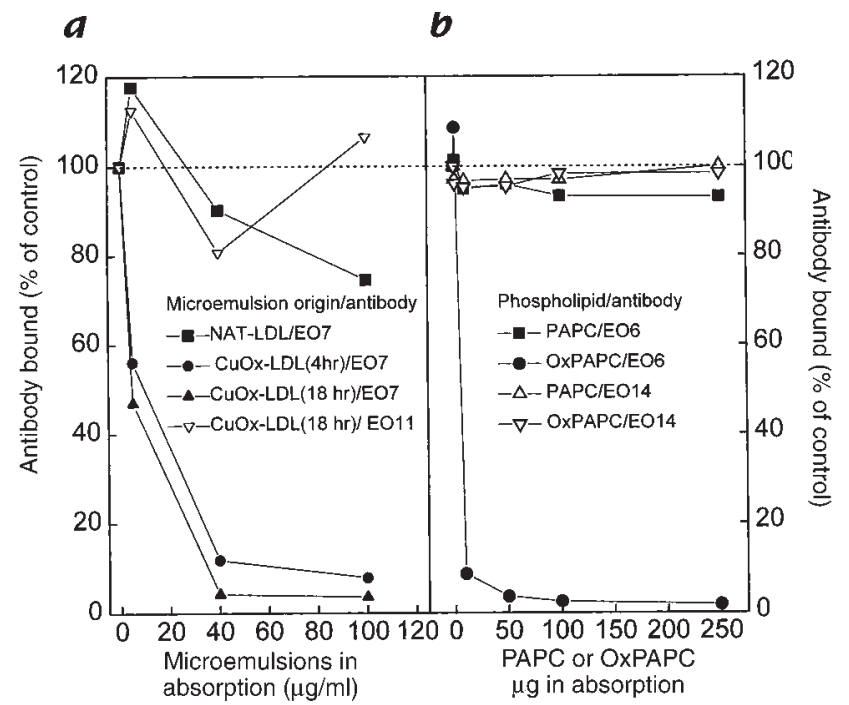

\section{Figure 6}

(a) Absorption experiment with microemulsions made from lipids extracted from native LDL and LDL oxidized with copper for $4 \mathrm{~h}$ or $18 \mathrm{~h}$ ( CuOx$\mathrm{LDL})$. In this experiment, EO7 and EO11 MABs $(10 \mu \mathrm{g} / \mathrm{ml}$; total of 1.0 $\mathrm{ml}$ ) were incubated for $1 \mathrm{~h}$ with increasing concentrations of lipid microemulsions in TBS buffer in the absence of any protein. After incubation the microemulsions were pelleted by ultracentrifugation, and the supernatants were tested for antibody binding to CuOx-LDL (EO7) or MDA-LDL (EO11) in a solid phase immunoassay. Control incubations with MABs without any lipid microemulsions were performed under identical conditions (including ultracentrifugation), and the results are expressed as percentage of control. (b) Absorption experiment with PAPC and OxPAPC. In this experiment, EO6 and EO14 MABs $(10 \mu \mathrm{g} / \mathrm{ml}$; total of $1.0 \mathrm{ml}$ ) were incubated for $1 \mathrm{~h}$ with increasing concentrations of PAPC and OxPAPC in PBS in the absence of any protein. After incubation, the immunocomplexes were pelleted with centrifugation, and the supernatants were tested for antibody binding to CuOx-LDL (EO6) or MDALDL (EO14) in a solid-phase immunoassay. Control incubations with $\mathrm{MABs}$ without any phospholipid were performed under identical conditions (including ultracentrifugation); the results are expressed as percentage of control. Each point is the mean of triplicate determinations. 


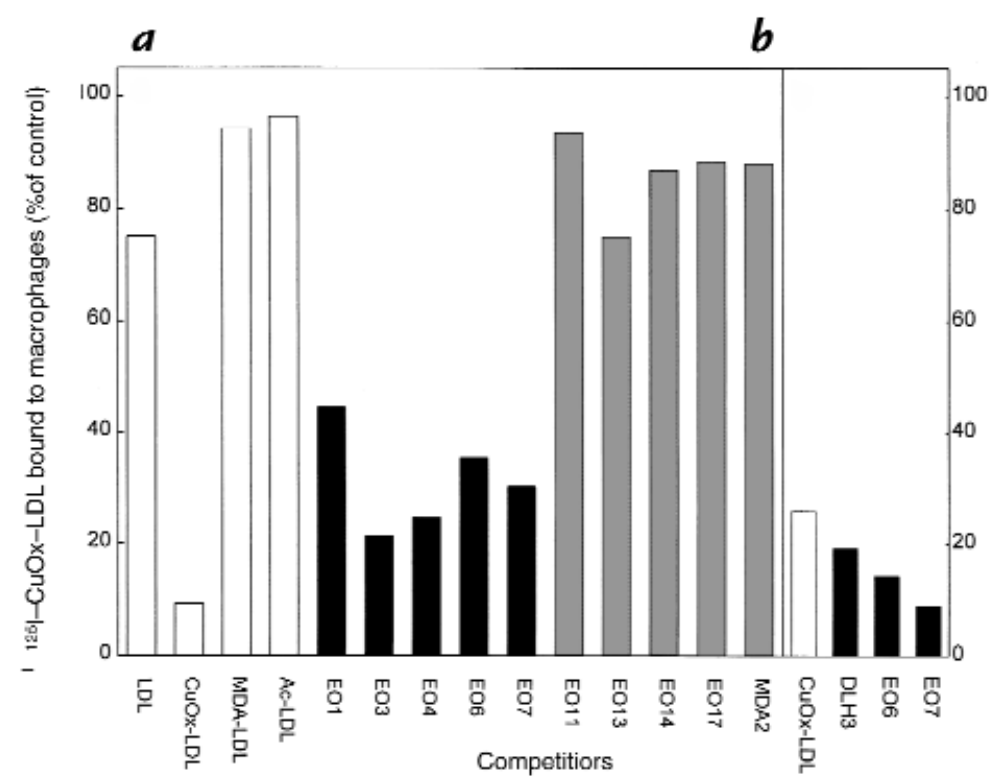

\section{Figure 7}

(a) Binding of $2 \mu \mathrm{g}(4 \mu \mathrm{g} / \mathrm{ml})$ of ${ }^{125} \mathrm{l}-\mathrm{CuOx}-\mathrm{LDL}$ to elicited mouse peritoneal macrophages at $4^{\circ} \mathrm{C}$ in the presence of $50 \mu \mathrm{g}(100 \mu \mathrm{g} / \mathrm{ml})$ of unlabeled LDL, CuOxLDL, MDA-LDL, acetylated LDL (Ac-LDL), natural mouse monoclonal IgM autoantibodies (EO1-EO17), and murine IgG MAB MDA2 as competitors. (b) Binding of $2 \mu \mathrm{g}(4 \mu \mathrm{g} / \mathrm{ml})$ of ${ }^{125} \mathrm{l}-\mathrm{CuOx}$-LDL to elicited mouse peritoneal macrophages (in another experiment) in the presence of $50 \mu \mathrm{g}(100 \mu \mathrm{g} / \mathrm{ml})$ of unlabeled CuOx-LDL and mouse MABs DLH3, EO6, and EO7. In both experiments ( $a$ and $b$ ), the data are expressed as the percentage of ${ }^{125} \mathrm{I}-\mathrm{CuOx}$-LDL bound in the absence of competitors ( $a: 1.3 \mu \mathrm{g} / \mathrm{mg}$ cell protein; $b: 0.5 \mu \mathrm{g} / \mathrm{mg}$ cell protein). Each bar is the mean of triplicate determinations. sively to the protein moiety of CuOx-LDL apoB (lane $c$ ). This binding was noted from apparently intact or even aggregated apoB to fragments as small as $40 \mathrm{kDa}$ (lane c). No EO6 binding was detected to the protein moiety of native LDL (Fig. 3, lane e), to the lipids extracted from $\mathrm{CuOx}$-LDL and handled in an identical manner (lane $b$ ), or to the lipids extracted from native LDL (lane $d$ ). MAB MB47, which binds to apoB, showed binding to the protein moiety of both the native LDL (Fig. 3, lane $b$ ), and $\mathrm{CuOx}$-LDL (lane j). Note that the native apoB in Fig. 3, lane $b$ had been delipidated before the SDS-PAGE and showed fragmentation. This is in contrast to a single band noted at $\sim 550 \mathrm{kDa}$ when intact LDL was subjected to SDS-PAGE. Despite this fragmentation, the native LDL did not bind EO6 (Fig. 3, lane e). MB47 did not bind to the lipids extracted from native LDL (Fig. 3, lane g) or CuOx-LDL (lane i). Small bands seen in Fig. 3, lanes $g$ and $i$, at $70 \mathrm{kDa}$ were shown in another blot to be due to binding of alkaline phosphatase-labeled avidin alone (data not shown).

Antibody binding to oxidized phospholipids. The initial site of oxidation of LDL (at least when mediated by copper in vitro) occurs in the PUFA of phospholipids on the surface of LDL (31). The main PUFA in LDL are linoleic (18:2) and arachidonic acid (20:4), the former being predominantly (65\%) bound in the cholesteryl esters, and the latter mostly (68\%) bound to the phospholipids (34). When linoleic acid, arachidonic acid, cholesteryl oleate, or cholesteryl linoleate were oxidized by exposure to air for 24 hours, they did not yield any $\mathrm{EO}^{-}$autoantibody binding activity (data not shown). To investigate if the epitopes for the $\mathrm{EO}^{-}$ autoantibodies are generated when phospholipids undergo oxidation, we oxidized synthetic PAPC by drying it on the surface of a glass tube and exposing it to air for 16-24 $h$, and then we tested the binding of the MABs to liposomes made from the native and oxidized PAPC (OxPA$\mathrm{PC})$. Fig. $4 a$ shows that all the $\mathrm{EO}^{-}$autoantibodies originally selected for binding to $\mathrm{CuOx}-\mathrm{LDL}$ (EO3, EO4, EO6, EO7), as well as antibody DLH3, bound to OxPAPC liposomes, but not to unoxidized PAPC liposomes. EO11, EO13, and EO14 that had originally been selected for binding to MDA-LDL showed almost no binding to OxPAPC or PAPC liposomes (Fig. 4a).

When PAPC is oxidized, a wide variety of oxidation products can be detected by mass spectrometry (28). Some of these compounds, such as POVPC and 1-palmitoyl-2-glutaroyl-sn-glycero-3-phosphocholine, are present in minimally modified LDL and have been shown to be biologically active, e.g., by inducing monocyte-endothelial interactions (28). We tested the binding of the MABs to synthetic POVPC $(27,28)$. MABs EO1, EO3, EO4, EO6, and EO7 which bound to CuOx-LDL (Fig.1) and OxPAPC (Fig. 4a), that also bound to POVPC (Fig 4a), whereas the MABs that bound to MDA-LDL (EO11, EO14, and EO17) did not. Monoclonal antibody

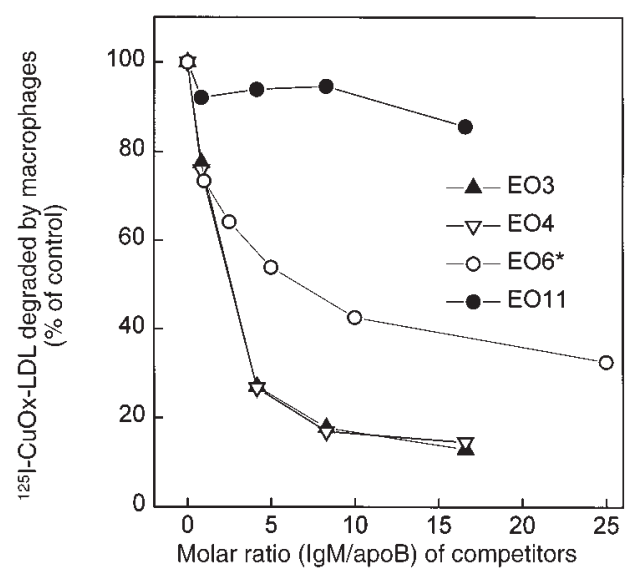

Figure 8

Degradation of $2 \mu \mathrm{g}(4 \mu \mathrm{g} / \mathrm{ml})$ of ${ }^{125} \mathrm{l}-\mathrm{CuOx}$-LDL by elicited mouse peritoneal macrophages in the presence of increasing concentrations of EOautoantibodies (EO3, EO4, EO6, and $E O 11)$ at $37^{\circ} \mathrm{C}$. Asterisk indicates that the degradation assay with EO6 was carried out in a separate experiment. The data are expressed as the percentage of ${ }^{125} \mid-C u O x-L D L$ degraded in the absence of competitors $\left(2.2 \mu \mathrm{g} / \mathrm{mg}\right.$ cell protein; ${ }^{*} 0.9$ $\mu \mathrm{g} / \mathrm{mg}$ cell protein). Addition of a 50 -fold excess of unlabeled CuOx-LDL inhibited the degradation of ${ }^{125} \mathrm{I}-\mathrm{CuOx}-\mathrm{LDL}$ to $4 \%$ of control. Each point is the mean of triplicate determinations. 


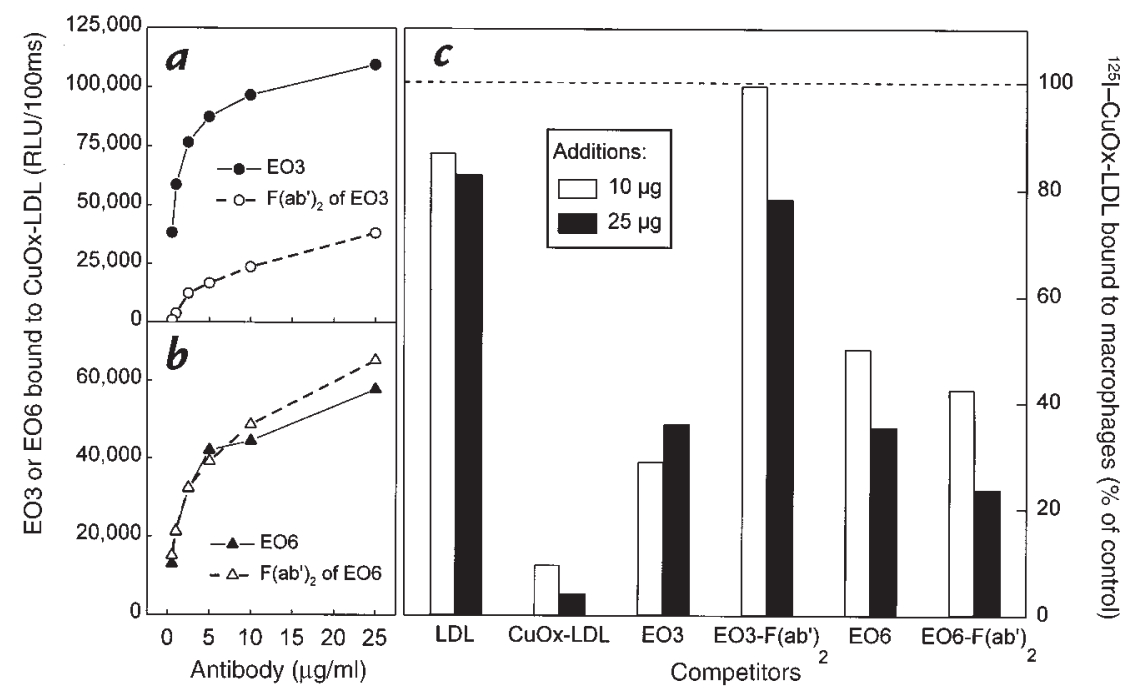

\section{Figure 9}

$(\boldsymbol{a}$ and $\boldsymbol{b})$ Immunoassay showing binding of EO3, EO6, and $\mathrm{F}\left(\mathrm{ab}^{\prime}\right)_{2}$ fragments of EO3 and EO6 to CuOx-LDL. Increasing concentrations of antibodies or $\mathrm{F}\left(\mathrm{ab}^{\prime}\right)_{2}$ were incubated in $\mathrm{CuOx}$ - $\mathrm{LDL}$-coated wells for $1 \mathrm{~h}$ at room temperature, and the amount of antibody bound was measured with alkaline phosphatase-labeled goat anti-mouse IgM antibody using chemiluminescent technique. (c) Binding of $2 \mu \mathrm{g}(4 \mu \mathrm{g} / \mathrm{ml})$ of ${ }^{125} \mathrm{l}-\mathrm{CuOx}$-LDL to elicited mouse peritoneal macrophages in the presence or absence of 10 and $20 \mu \mathrm{g}$ of unlabeled LDL, CuOx-LDL, monoclonal autoantibodies EO3 and EO6, and $\mathrm{F}\left(\mathrm{ab}^{\prime}\right)_{2}$ fragments of EO3 and EO6 as competitors. The data are expressed as the percentage of $125 \mathrm{I}-\mathrm{CuOx}$-LDL bound in the absence of competitors $(0.6 \mu \mathrm{g} / \mathrm{mg}$ cell protein). Each value is the mean of triplicate determinations.

DLH3 also bound to POVPC, as reported previously (27). The specificity of the $\mathrm{EO}^{-}$autoantibodies EO1-EO7 for an aldehyde in the $s n 2$ position of the phospholipid was demonstrated by showing that the 5-carbon carboxylic analogue of POVPC (1-palmitoyl-2-glutaroyl-sn-glycero3-phosphocholine) did not react with any of these antibodies (data not shown). To determine if the $\mathrm{EO}^{-}$ autoantibodies would recognize degradation products that are generated from the oxidized fatty acids (without the phospholipid backbone), we used pure valeraldehyde, valeric acid, 5-amino valeric acid, amyl amine, and pentanol as plated antigens. None of the $\mathrm{EO}^{-}$autoantibodies showed any binding activity against these compounds (data not shown).

The above data suggest that an oxidized phospholipid with an aldehyde in the $\operatorname{sn} 2$ position is required for antibody recognition of the isolated lipid. Because the $\mathrm{EO}^{-}$ autoantibodies also recognized the modified protein of OxLDL (Figs. 2 and 3), we prepared reduced Schiff-base adducts of POVPC with bovine serum albumin (BSA). As shown in Fig. 4b, EO6 clearly binds to such covalent adducts. Although it is not clear how EO6 reacts with both the phospholipid containing free aldehyde and the lipid-protein adduct, we speculate that the free aldehyde, which would be more polar, can interact via hydrogen bonding with the PC-headgroup to generate a structure immunologically similar to that occuring with Schiff-base formation.

Competition immunoassays were then performed to demonstrate the presence of OxPAPC and POVPC epitopes on $\mathrm{CuOx}$-LDL. Fig. $5 a$ shows that the binding of EO6 to CuOx-LDL was totally competed by OxPAPC liposomes, as well as by intact $\mathrm{CuOx}$-LDL, whereas unoxidized PAPC liposomes or native LDL showed no competition for binding. Fig. $5 b$ shows that the binding of EO6 to POVPC was almost completely competed by $\mathrm{CuOx}$ LDL, but not by MDA-LDL, BSA, or unoxidized PAPC liposomes. These data strongly suggest that POVPC or POVPC-apoB adducts are present on CuOx-LDL.

Antibody binding to the lipid moiety of $O x L D L$ in the absence of protein. The reactive aldehydes generated from the breakdown products of lipid peroxidation during LDL oxidation could react with lysine (or histidine) residues of any closely associated protein. Thus, in theory, any protein present in the microtiter wells could react with the oxidative breakdown products of the phospholipids (and other lipids) and form lipid-protein adducts. This could even happen with the BSA used for blocking the nonspecific binding sites in the microtiter wells. To investigate the binding of the $\mathrm{EO}^{-}$autoantibodies to the lipid microemulsions in the absence of any added protein (except the antibodies themselves), we incubated the lipid microemulsions with the antibodies in a fluid phase assay in TBS buffer for one hour to allow binding and then spun down the microemulsions in an ultracentrifuge $(100,000 \mathrm{~g})$. The supernatants containing unbound antibodies were then tested for binding to CuOx-LDL (EO7) or MDA-LDL (EO11) in the solid phase chemiluminescent immunoassay. Figure $6 a$ shows that MAB EO7 was absorbed by lipid microemulsions prepared from $\mathrm{CuOx}$-LDL oxidized for 4 or 18 hours in the absence of any other protein, whereas it was not absorbed by lipid microemulsions prepared from native LDL. Control antibody EO11 was not absorbed by the lipid microemulsions prepared from 18-hour CuOx-LDL. To determine whether EO6 binds to OxPAPC in the absence of any protein (except EO6 itself), we incubated OxPAPC (or PAPC) and EO6 in phosphate-buffered saline for one hour, spun down the immunocomplexes, and tested the supernatant for remaining binding activity in a 


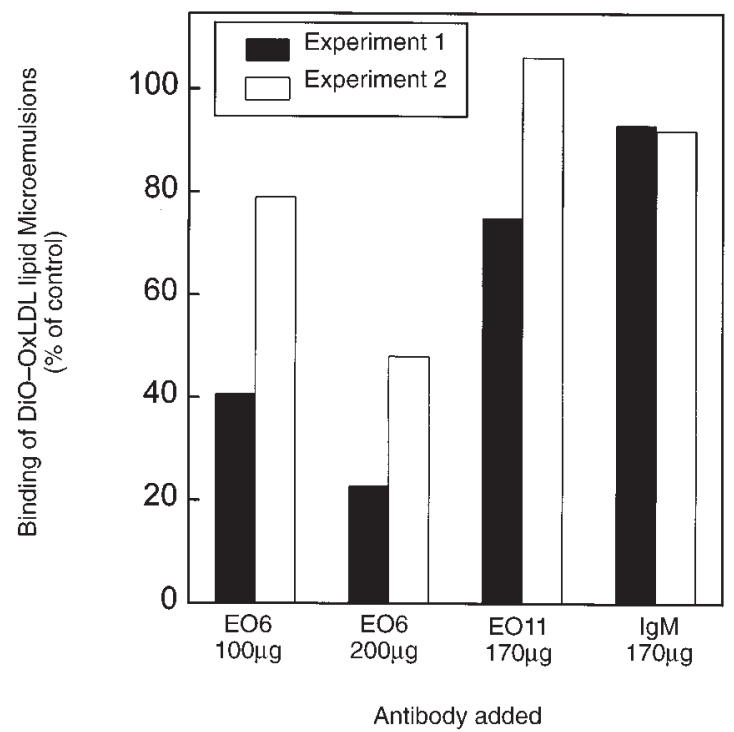

Figure 10

Binding of DiO-labeled CuOx-LDL lipid microemulsions to mouse peritoneal macrophages in the presence of unlabeled EO6, EO11, or control mouse IgM as competitors. DiO-labeled CuOx-OxLDL lipid microemulsions were incubated with resident mouse peritoneal macrophages in the presence of MABs EO6, EO11, or control mouse IgM for $2 \mathrm{~h}$ at $4^{\circ} \mathrm{C}$. The cells were washed and the mean fluorescence intensity was measured using flow cytometry (20,000 events). The data are expressed as the percentage of DiO-labeled CuOx-OxLDL microemulsions bound to the macrophages in the absence of competitors. Each bar is a single measurement. The figure shows two separate experiments with different $\mathrm{CuOx}$ OxLDL lipid microemulsions.

chemiluminescent immunoassay. Fig. $6 b$ shows that EO6 was absorbed completely by OxPAPC, but not by native PAPC, in the complete absence of protein in the incubation medium. Control absorptions with MAB EO14, which does not bind to OxPAPC (Fig. 4a), demonstrated that neither PAPC nor OxPAPC inhibited the binding of EO14 to MDA-LDL (ruling out nonspecific interactions of these lipids on antibody function). These data suggest that the epitopes for MABs EO1-EO7 are generated when intact phospholipids containing PUFAs undergo oxidation and that the antibodies do not require a protein backbone (such as apoB) for the epitope recognition.

Stoichiometry of EO6 binding to $\mathrm{C} u O x-L D L$. The binding affinity for EO6 binding to $\mathrm{CuOx}$-LDL was estimated by incubating increasing concentrations of ${ }^{125} \mathrm{I}-\mathrm{CuOx}$ - LDL $(0-20 \mu \mathrm{g} / \mathrm{ml})$ in wells were coated with EO6. After a fourhour incubation at room temperature, the unbound ${ }^{125} \mathrm{I}$ $\mathrm{CuOx}$-LDL was washed off and the wells counted for radioactivity. The calculated dissociation constant $\left(K_{\mathrm{d}}\right)$ values for EO6 binding to ${ }^{125} \mathrm{I}-\mathrm{CuOx}$ - $\mathrm{LDL}\left(1 / 2 \mathrm{~B}_{\max }\right)$ were $2.9 \times 10^{-8} \mathrm{M}$ and $4.1 \times 10^{-8} \mathrm{M}$ in two separate experiments with different OxLDL preparations. To determine the number of binding sites per OxLDL particle, a different fluid phase assay was used in which increasing amounts of unlabeled EO6 were added to a fixed amount of ${ }^{125} \mathrm{I}-\mathrm{CuOx}$-LDL (100 ng/well). These mixtures were incubated in EO6-coated microtiter wells overnight at $4^{\circ} \mathrm{C}$ and the amount of ${ }^{125} \mathrm{I}-\mathrm{CuOx}$-LDL bound to EO6 was measured. In these experiments, there were two different kinds of binding sites: one similar to those obtained in experiments above $\left(4.7 \times 10^{-8} \mathrm{M}\right)$ and another with even higher affinity $\left(7.9 \times 10^{-11} \mathrm{M}\right)$. There were approximately five high-affinity sites on one $\mathrm{CuOx}$-LDL particle. The curve for the low-affinity binding was quite shallow and yielded estimates between 223 and 310 binding sites per CuOx-LDL particle (data not shown).

The effect of MABs on the binding of $O x L D L$ to macrophages. To investigate if the oxidized phospholipid epitopes recognized by the MABs would also be involved in the recognition of OxLDL by macrophage scavenger receptors, we incubated mouse elicited peritoneal macrophages with $2 \mu \mathrm{g}$ of ${ }^{125} \mathrm{I}-\mathrm{CuOx}$-LDL in the presence of $50 \mu \mathrm{g}$ of unlabeled $\mathrm{EO}^{-}$autoantibodies as competitors $\left(\right.$ at $\left.4^{\circ} \mathrm{C}\right)$. These amounts yield molar ratios of IgM to apoB (as a marker of LDL particles) of $\sim 15: 1$. As shown in Fig. $7 a$, all the $\mathrm{EO}^{-}$autoantibodies that bound to $\mathrm{CuOx}$-LDL, OxPAPC, and POVPC (EO1, EO3, EO4, EO6, and EO7) also inhibited $60 \%-80 \%$ of the binding of ${ }^{125} \mathrm{I}-\mathrm{CuOx}$-LDL to macrophages. MABs binding predominantly to MDA-LDL (EO11, EO14, EO17, and MDA2) did not influence the binding (Fig. 7a). Antibody EO13, which bound to CuOx-LDL and MDA-LDL, but bound very poorly to oxidized phospholipids, did not inhibit the binding. In another experiment (Fig. 7b), EO6 and EO7 inhibited the binding of ${ }^{125} \mathrm{I}-\mathrm{CuOx}$-LDL to macrophages to an even greater extent (86\% and $91 \%$, respectively), and the MAB DLH3 also showed significant inhibition of binding (80\%).

We also tested the ability of the MABs to inhibit the binding of ${ }^{125}$ I-MDA-LDL to macrophages (data not shown). None of the antioxidized phospholipid autoantibodies (EO1, EO3, EO4, EO6, and EO7) inhibited binding, and surprisingly, none of the anti-MDA-LDL autoantibodies inhibited the binding either (EO11, EO13, EO14, and EO17) (data not shown), even though we had earlier shown that these latter antibodies bind strongly to MDA-LDL (Fig. 1). These data demonstrate again that the antibodies were not inhibiting the binding of OxLDL nonspecifically.

The effect of MABs on the degradation of OxLDL by macrophages. Each of the $\mathrm{EO}^{-}$autoantibodies that bound to oxidized phospholipids (e.g., EO3, EO4, and EO6), also inhibited degradation of ${ }^{125} \mathrm{I}-\mathrm{CuOx}$-LDL by macrophages in a dose-dependent fashion, whereas EO11 showed no effect (Fig. 8). The inhibition reached saturation at a molar ratio of 10 added IgM molecules to one apoB molecule in this experiment. In other experiments, with different $\mathrm{CuOx}$-LDL preparations, the molar ratios needed to maximally inhibit the binding and degradation of ${ }^{125} \mathrm{I}-\mathrm{CuOx}$-LDL by macrophages varied from $\sim 8$ to 25 IgM molecules to one apoB molecule. This variation is most likely caused by differences in the OxLDL preparations; i.e., some preparations may be more heavily oxidized than others and thus may express different numbers of epitopes.

The effect of $F\left(a b^{\prime}\right)_{2}$ fragments of the MABs on the binding of $O x L D L$ to macrophages. The molecular weight of IgM is $\sim 900 \mathrm{kDa}$. To reduce the possibility that the $\mathrm{EO}^{-}$autoantibody IgM molecules could be masking the epitopes recognized by scavenger receptors on macrophages simply by nonspecific steric hindrance, we prepared $\mathrm{F}\left(\mathrm{ab}^{\prime}\right)_{2}$ frag- 
ments of EO3 and EO6 antibodies. When binding to $\mathrm{CuOx}-\mathrm{LDL}$ was tested in an immunoassay, the EO6 $\mathrm{F}\left(\mathrm{ab}^{\prime}\right)_{2}$ fragments bound as well as the intact EO6 IgM molecules, whereas the EO3 $\mathrm{F}\left(\mathrm{ab}^{\prime}\right)_{2}$ fragments lost most of their binding activity (Fig. 9, $a$ and $b$ ). Accordingly, the EO6 F $\left(\mathrm{ab}^{\prime}\right)_{2}$ fragments inhibited the ${ }^{125} \mathrm{I}-\mathrm{CuOx}$-LDL binding to macrophages to the same extent as the intact EO6 IgM molecules, whereas the EO3 $\mathrm{F}\left(\mathrm{ab}^{\prime}\right)_{2}$ fragments did not inhibit the binding (Fig. 9c).

The effect of MABs on the binding of microemulsions made from OXLDL lipid to macrophages. The data above suggest that the $\mathrm{EO}^{-}$autoantibodies can inhibit uptake of OxLDL by murine macrophages, and that they bind to both the isolated lipid and protein moieties of $\mathrm{CuOx}$ LDL. To investigate if the $\mathrm{EO}^{-}$autoantibodies could inhibit macrophage recognition of the isolated lipid moiety of OxLDL, we incubated resident mouse peritoneal macrophages with DiO-labeled lipid microemulsions in the presence of 100 or $200 \mu \mathrm{g}$ of unlabeled $\mathrm{EO}^{-}$ autoantibodies as competitors $\left(4^{\circ} \mathrm{C}\right)$ and measured the binding with flow cytometry. Figure 10 demonstrates that EO6 substantially inhibited the binding of two separate preparations of lipid microemulsions prepared from OxLDL. In contrast, EO11 (which binds predominantly to MDA-LDL) and control mouse IgM showed no effect on the binding (Fig. 10). DiO-labeled microemulsions of native LDL showed no binding to resident macrophages (data not shown).

POVPC-modified BSA inhibits the degradation of OxLDL by macrophages. To further test the hypothesis that POVPC was a ligand on OxLDL that mediated macrophage recognition, we tested the ability of POVPC-modified albumin to inhibit the uptake of ${ }^{125} \mathrm{I}-\mathrm{CuOxLDL}$. POVPC-BSA was readily recognized by EO6 (Fig. 4b). As shown in Fig. 11, whereas native BSA had no impact, both unlabeled OxLDL and POVPC-BSA inhibited uptake and degradation $>80 \%$.

\section{Discussion}

In this paper we demonstrate that several monoclonal autoantibodies cloned from apoE-deficient mice bind to oxidized phospholipid epitopes and to both the oxidized lipid moiety and the oxidized protein moiety of OxLDL. These same antibodies block the binding, uptake, and degradation of OxLDL and OxLDL lipids by macrophages. Furthermore, an adduct of POVPC with BSA also blocks the uptake of OxLDL. These data suggest that oxidized phospholipids represent one class of ligands on OxLDL that mediates its binding and uptake by macrophage scavenger receptors.

In earlier studies, we demonstrated that apoE-deficient mice, which have extensive hypercholesterolemia and associated atherosclerosis, have exceedingly high autoantibody titers to various epitopes of OxLDL (8). These very high titers allowed us to clone a series of monoclonal autoantibodies to OxLDL using the spleens of two apoE-deficient mice that had not been exogenously immunized (10). In our initial screening strategy (10), we used several model epitopes of OxLDL (and other proteins, such as HDL, BSA, and polylysine) and demonstrated that most of these $\mathrm{EO}^{-}$autoantibodies were binding to epitopes of adducts of oxidized lipid and protein. The results shown in this report demonstrate that not only do some of the $\mathrm{EO}^{-}$autoantibodies bind to neoepitopes formed by covalent adduct formation between oxidized lipids and apoB, as demonstrated by immunoassays of delipidated apoB and Western blot analysis, but they also bind to the proteinfree lipid moiety of OxLDL. Although a very small amount of protein was detected in lipids extracted from the OxLDL $(\sim 1.3 \%$ of the initial protein content was carried over to the lipid fraction; ref. 25), our demonstration that oxidation of synthetic PAPC also gave rise to the epitopes strongly suggests that some of the antibodies can recognize oxidized phospholipids in OxLDL both as isolated lipid and as oxidized lipid adducts covalently attached to apoB. Furthermore, we show that the monoclonals that inhibited macrophage binding specifically bound to POVPC, an oxidized phospholipid present in OxPAPC and mm-LDL (28). Figures 5 and 6 clearly demonstrate that epitopes found in oxidized PAPC and POVPC are present on OxLDL. Furthermore, EO6 recognizes POVPC present as isolated lipid (Fig. 4), or as an adduct with BSA (Fig. 4b). The fact that oxidation of fatty acids (linoleic acid and arachidonic acid), or cholesteryl esters (cholesteryl-oleate and cholesteryllinoleate), or various analogues of oxovaleraldehyde, did not yield any binding activity, further suggests that the "intact" oxidized phospholipid is important for antibody binding, and by inference, ligand formation. The actual spatial presentation of the oxidized phospholipids, however, seems less clear for the antibody binding activity because the MABs bound to the epitopes when the oxidized lipids were plated in organic solvent, or when present as microemulsions or when present as lipid-protein adducts in denatured form on gels in the Western blot analysis.

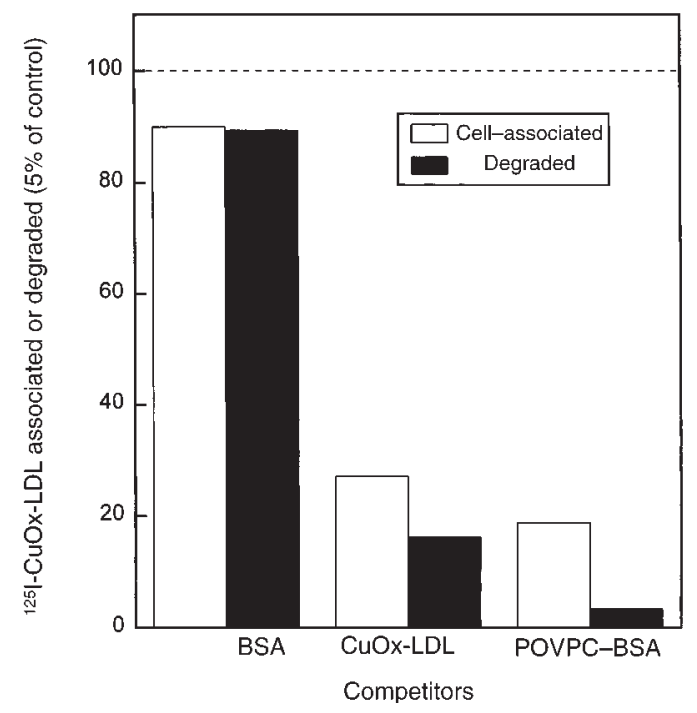

Figure 11

Cell association $\left(37^{\circ} \mathrm{C}\right)$ and degradation of $2 \mu \mathrm{g}$ of ${ }^{125} \mathrm{I}-\mathrm{CuOx}-\mathrm{LDL}$ by mouse peritoneal macrophages in presence of $50 \mu \mathrm{g}$ of BSA, unlabeled CuOx-LDL, or POVPC-BSA adduct. The data are expressed as the percentage of ${ }^{125}$-CuOx-LDL associated with cells or degraded in the absence of competitors ( 0.95 and $0.32 \mu \mathrm{g} / \mathrm{mg}$ cell protein, respectively). Each bar is the mean of duplicate determinations. 
These data strongly support the hypothesis that oxidized phospholipid epitopes, such as POVPC, are one class of ligands on OxLDL for macrophage scavenger receptor recognition. Although we cannot absolutely exclude the possibility that the $\mathrm{EO}^{-}$autoantibodies and DLH3 inhibited OxLDL binding to macrophages by binding to oxidized phospholipids on the surface of OxLDL and thereby masking other nearby epitopes, several lines of evidence argue against this possibility. First, $\mathrm{F}\left(\mathrm{ab} \mathrm{b}_{2}\right)_{2}$ fragments of EO6, which were one-sixth the size, were equally effective as intact EO6. Second, EO13, which bound to CuOx-LDL and MDA-LDL, but not to oxidized phospholipids, failed to inhibit binding and degradation of OxLDL. Third, the $\mathrm{EO}^{-}$autoantibodies to MDA-LDL, including EO13, did not inhibit the binding of MDA-LDL to macrophages. This strongly suggests that the inhibition of the antioxidized phospholipid antibodies was not due to steric hindrance. Indeed, the effects of the blocking IgMs were restricted to those antibodies that bound to oxidized phospholipid such as POVPC. Nonspecific effects were further excluded by the demonstration that IgMs that did not bind to OxLDL did not inhibit binding to the macrophages. We have not yet fully elucidated all of the potentially modified phospholipid epitopes that may be structurally and immunologically similar to POVPC, that may also act as epitopes for the antibodies and as ligands. In preliminary experiments, EO6 also recognizes 1-palmitoyl-2-(9-oxononanoyl)-phosphocholine (PONPC), the nine-carbon aldehyde analogue of POVPC, either as free lipid or when covalently attached to BSA (data not shown). In a similar manner, Itabe et al. (27) reported that DLH3 also recognizes PONPC, as well as an adduct of PONPC, with a COOH-terminal peptide of peroxisomal membrane protein. Thus, there may be a number of analogues of oxidized phospholipids that are ligands for OxLDL recognition. Finally, the direct demonstration that a POVPC-BSA adduct directly inhibited the binding and degradation of OxLDL strongly supports the role of POVPC as an important ligand.

As pointed out earlier, OxLDL is a very complex structure, and it is likely that there are multiple ligands responsible for macrophage recognition, just as there appear to be several different macrophage receptors for OxLDL. Because a variety of modifications of lysine residues of LDL, such as acetylation, maleylation, or modification with MDA or 4-HNE all lead to enhanced macrophage uptake, it was generally assumed that protein modifications alone were responsible for macrophage uptake. Indeed, Parthasarathy et al. (24) delipidated OxLDL and resolubilized the oxidized apoprotein in octylglucoside. They showed that the protein moiety of OxLDL was taken up and degraded by macrophages at almost the same high rate as intact OxLDL and that this uptake was competed by intact OxLDL. They concluded that during oxidative modification new epitopes are generated on the apoprotein that are responsible for the recognition by scavenger receptors (24). Steinbrecher and colleagues (35) initially demonstrated that oxidation of LDL resulted in modification of lysine residues. Subsequently, they demonstrated that LDL (and other proteins) modified with oxidation products generated from arachidonic acid by thermal autoxi- dation also had enhanced degradation by macrophages, which could be blocked by MABs specific for adducts of oxidation products with lysine (36). This also suggested that derivatization of lysine residues with specific lipid peroxidation products is necessary and sufficient for binding of proteins to the scavenger receptors. However, another study by Hoppe et al. (37) showed that LDL modified by selected lysine group-specific chemical reagents expected to occur in LDL oxidation as a result of lysine derivatization by lipid peroxidation products (such as oxononanal, hexanedione, and trimethylpyrylium) had an enhanced uptake and degradation by macrophages.

The possibility that the oxidized lipid moiety of OxLDL could also serve as ligand for macrophages had not been considered in the studies described above. However, a very recent study by Terpstra et al. (25) used competition studies to demonstrate that the binding and uptake of intact ${ }^{125} \mathrm{I}-\mathrm{OxLDL}$ could be strongly inhibited by microemulsions made either from lipids extracted from OxLDL or by OxPAPC, implying that the lipid moiety of OxLDL may play an important role in macrophage recognition. In the present paper, for the first time, we use carefully characterized MABs, as well as their $\mathrm{F}\left(\mathrm{ab} \mathrm{b}^{\prime}\right)_{2}$ fragments, to define epitopes on OxLDL responsible for binding to macrophages. Remarkably, all of the $\mathrm{EO}^{-}$autoantibodies that blocked macrophage uptake of OxLDL also bound to both the lipid and protein moiety of OxLDL. This suggests that either oxidized phospholipids or lipid-protein adducts, or, both could serve as ligands for macrophage recognition. The widespread generation of such epitopes over both the lipid and protein surface of OxLDL could explain why OxLDL is so avidly bound by macrophages and why the $\mathrm{EO}^{-}$autoantibodies are so effective in blocking this binding. Indeed, as shown in Fig. 10, the antibodies block binding of lipid microemulsions prepared from OxLDL. Further studies are under way to determine the ability of the antibodies to block the uptake of either the lipid or the isolated protein of OxLDL by macrophages and to delineate which of the known OxLDL receptors are responsible for recognition of this class of ligands. Considering the complexity of the ligands on OxLDL and the different OxLDL receptors, the degree to which the $\mathrm{EO}^{-}$autoantibodies to oxidized phospholipids inhibited OxLDL uptake is surprising. Although these may be important, or even dominant ligands, it also must be considered that there may be hot spots on OxLDL (e.g., where polyunsaturated fatty acids occur) such that clustering of ligands for the various OxLDL receptors occurs. Thus, blocking one legitimate ligand may block other equally competent ligands as well.

We and others demonstrated previously that autoantibodies to OxLDL occur in plasma and atherosclerotic lesions of humans and animal models. The present studies are also important because for the first time, they characterize some of the actual epitopes to which many of the autoantibodies to OxLDL bind. In fact, it is of considerable interest that most of the autoantibodies that we cloned from apoE-deficient mice on the basis of their ability to bind to OxLDL bind to oxidized phospholipids. Both the $\mathrm{EO}^{-}$autoantibodies and DLH3 have been shown to immunostain atherosclerotic lesions and 
both recognize epitopes on circulating LDL $(10-12,26)$. Antibody DLH3 was generated by immunizing mice with human atheromatous material. It is remarkable that DLH3 and EO6 bind to a very closely related epitope (Fig. 1b). Indeed, they both bind to POVPC and PONPC. These data together with the recent observations of Watson et al. (28) demonstrate that oxidized phospholipids are prominent components of OxLDL and of atherosclerotic lesions, and in particular are strong immunogens. As we reported recently (21), many of the so-called antiphospholipid antibodies found in humans are directed against oxidized phospholipids or oxidized phospholipid-protein adducts (30). We suggest that oxidized phospholipids, present in OxLDL or as components of atherosclerotic lesions, as well as those present on other oxidatively damaged structures, such as cellular membranes, may all give rise to common epitopes and common autoantibodies.

These findings also indicate that oxidized phospholipid epitopes are involved in the recognition of OxLDL by macrophages, and that apoE-deficient mice have endogenously generated IgM autoantibodies that can bind to these epitopes and inhibit OxLDL uptake. It is unknown at present whether such antibodies have any biological significance. However, it is known that immunization of hypercholesterolemic rabbits and mice with OxLDL leads to an amelioration of the progression of atherosclerosis (38-42). An interesting question is whether the type of autoantibodies described in this paper could play a role in this protective effect? We have reported previously that IgM antibodies to oxidation-specific epitopes are present in human subjects (10, 43). Because the epitopes of the $\mathrm{EO}^{-}$autoantibodies are present in human atherosclerotic lesions and on human circulating LDL (10), it can be speculated that similar autoantibodies are likely to be present in humans as well. Further studies will be needed to determine the relevance of such immunological responses to oxidized phospholipid neoepitopes.

\section{Acknowledgments}

The authors thank Daniel Steinberg for his continued advice and support, as well as Valeska Terpstra and Kristin Gillotte for helpful discussions and insights. These studies were supported by National Institutes of Health grants HL56989 (La Jolla Specialized Center of Research), HL57505 (to J.L. Witztum), and HL30568 (to J.A. Berliner), and by a Postdoctoral Research Fellowship of the American Heart Association, California Affiliate (to S. Hörkkö).

1. Palinski, W., et al. 1989. Low density lipoprotein undergoes oxidative modification in vivo. Proc. Natl. Acad. Sci. USA. 86:1372-1376.

2. Ylä-Herttuala, S., et al. 1989. Evidence for the presence of oxidatively modified low density lipoprotein in atherosclerotic lesions of rabbit and man. J. Clin. Invest. 84:1086-1095.

3. Ylä-Herttuala, S., Palinski, W., Rosenfeld, M.E., Steinberg, D., and Witztum, J.L. 1990. Lipoproteins in normal and atherosclerotic aorta. Eur. Heart J. 11(Suppl. E):88-99.

4. Haberland, M.E., Fong, D., and Cheng, L. 1988. Malondialdehyde-altered protein occurs in atheroma of Watanabe heritable hyperlipidemic rabbits. Science. 241:215-218.

5. Boyd, H.C., Gown, A.M., Wolfbauer, G., and Chait, A. 1989. Direct evidence for a protein recognized by a monoclonal antibody against oxidatively modified LDL in atherosclerotic lesions from a Watanabe heritable hyperlipidemia rabbit. Am. J. Pathol. 135:815-825.

6. Rosenfeld, M.E., Palinski, W., Ylä-Herttuala, S., Butler, S., and Witztum, J.L. 1990. Distribution of oxidation specific lipid-protein adducts and apolipoprotein B in atherosclerotic lesions of varying severity from WHHL rabbits. Arteriosclerosis. 10:336-349.

7. Hammer, A., et al. 1995. Generation, characterization, and histochemical application of monoclonal antibodies selectively recognizing oxidatively modified apoB-containing serum lipoproteins. Arterioscler. Thromb. Vasc. Biol. 15:704-713.

8. Palinski, W., et al. 1994. Apoprotein E-deficient mice are a model of lipoprotein oxidation in atherogenesis: demonstration of oxidation-specific epitopes in lesions and high titers of autoantibodies to malondialdehyde-lysine in serum. Arterioscler. Thromb. 14:605-615.

9. Palinski, W., Tangirala, R.K., Miller, E., Young, S.G., and Witztum, J.L. 1995. Increased autoantibody titers against epitopes of oxidized low density lipoprotein in LDL receptor-deficient mice with increased atherosclerosis. Arterioscler. Thromb. Vasc. Biol. 15:1569-1576.

10. Palinski, W., et al. 1996. Cloning of monoclonal autoantibodies to epitopes of oxidized lipoproteins from apo E-deficient mice. Demonstration of epitopes of oxidized LDL in human plasma. J. Clin. Invest. 98:800-814.

11. Itabe, H., et al. 1996. Sensitive detection of oxidatively modified low density lipoprotein using a monoclonal antibody. J. Lipid Res. 37:45-53.

12. Tamai, O., et al. 1997. Single LDL apheresis improves endotheliumdependent vasodilatation in hypercholesterolemic humans. Circulation. 95:76-82.

13. Holvoet, P., Theilmeier, G., Shivalkar, B., Flameng, W., and Collen, D. 1998. LDL hypercholesterolemia is associated with accumulation of oxidized LDL, atherosclerotic plaque growth, and compensatory vessel enlargement in coronary arteries of miniature pigs. Arterioscler. Thromb. Vasc. Biol. 18:415-422.

14. Sevanian, A., et al. 1997. LDL- is a lipid hydroperoxide-enriched circulating lipoprotein. J. Lipid. Res. 38:419-428.

15. Quinn, M.T., Parthasarathy, S., Fong, L.G., and Steinberg, D. 1987. Oxidatively modified low density lipoproteins: a potential role in recruitment and retention of monocyte/macrophages during atherogenesis. Proc. Natl. Acad. Sci. USA. 84:2995-2998.

16. McMurray, H.F., Parthasarathy, S., and Steinberg, D. 1993. Oxidatively modified low density lipoprotein is a chemoattractant for human T lymphocytes. J. Clin. Invest. 92:1004-1008.

17. Hessler, J.R., Morel, D.W., Lewis, L.J., and Chisolm, G.M. 1983. Lipoprotein oxidation and lipoprotein-induced cytotoxicity. Arteriosclerosis. 3:215-222.

18. Rajavashisth, T.B., et al. 1990. Induction of endothelial cell expression of granulocyte and macrophage colony-stimulating factors by modified low-density lipoproteins. Nature. 344:254-257.

19. Cushing, S.D., et al. 1990. Minimally modified low density lipoprotein induces monocyte chemotactic protein 1 in human endothelial cells and smooth muscle cells. Proc. Natl. Acad. Sci. USA. 87:5134-5138.

20. Esterbauer, H., Gebicki, J., Puhl, H., and Jürgens, G. 1992. The role of lipid peroxidation and antioxidants in oxidative modification of LDL. Free Radical Biol. Med. 13:341-390.

21. Hörkkö, S., et al. 1996. Antiphospholipid antibodies are directed against epitopes of oxidized phospholipids: recognition of cardiolipin by monoclonal antibodies to epitopes of oxidized low-density lipoprotein. J. Clin. Invest. 98:815-825.

22. Fong, L.G., Parthasarathy, S., Witztum, J.L., and Steinberg, D. 1987. Nonenzymatic oxidative cleavage of peptide bonds in apoprotein B-100. J. Lipid Res. 28:1466-1477.

23. Palinski, W., et al. 1990. Antisera and monoclonal antibodies specific for epitopes generated during oxidative modification of low density lipoprotein Arteriosclerosis. 10:325-335.

24. Parthasarathy, S., Fong, L.G., Otero, D., and Steinberg, D. 1987. Recognition of solubilized apoproteins from delipidated, oxidized low density lipoprotein (LDL) by the acetyl-LDL receptor. Proc. Natl. Acad. Sci. USA. 84:537-540.

25. Terpstra, V., Bird, D., and Steinberg, D. 1998. Evidence that the lipid moiety of oxidized low density lipoprotein plays a role in its interaction with macrophage receptors. Proc. Natl. Acad. Sci. USA. 95:1806-1811.

26. Itabe, H., et al. 1994. A monoclonal antibody against oxidized lipoprotein recognizes foam cells in atherosclerotic lesions. J. Biol. Chem. 269:15274-15279.

27. Itabe, H., et al. 1996. Oxidized phosphatidylcholines that modify proteins. Analysis by monoclonal antibody against oxidized low density lipoprotein. J. Biol. Chem. 271:33208-33217.

28. Watson, A.D., et al. 1997. Structural identification by mass spectrometry of oxidized phospholipids in minimally oxidized low density lipoprotein that induce monocyte/endothelial interactions and evidence for their presence in vivo. J. Biol. Chem. 272:13597-13607.

29. Young, S.G., Witztum, J.L., Casal, D.C., Curtiss, L.K., and Bernstein, S. 1986. Conservation of the low density lipoprotein receptor-binding domain of apoprotein B. Demonstration by a new monoclonal antibody, MB47. Arteriosclerosis. 6:178-188.

30. Hörkkö, S., Miller, E., Branch, D.W., Palinski, W., and Witztum, J.L. 1997. The epitopes for some antiphospholipid antibodies are adducts of oxidized phospholipid and beta-2 glycoprotein 1 (and other proteins). Proc. Natl. Acad. Sci. USA. 94:10356-10361. 
31. Reaven, P., et al. 1993. Effects of oleate-rich and linoleate-rich diets on the susceptibility of low density lipopotein to oxidative modification in mildly hypercholesterolemic subjects. J. Clin. Invest. 91:668-676.

32. Goldstein, J.L., Basu, S.K., and Brown, M.S. 1983. Receptor-mediated endocytosis of low-density lipoprotein in cultured cells. Methods Enzymol. 98:241-260.

33. Lowry, O.H., Rosebrough, N.J., Farr, A.L., and Randall, R.J. 1951. Protein measurement with the Folin phenol reagent. J. Biol. Chem. 193:265-275.

34. Esterbauer, H., Dieber-Rotheneder, M., Waeg, G., Striegl, G., and Jurgens, G. 1990. Biochemical, structural, and functional properties of oxidized low-density lipoprotein. Chem. Res. Toxicol. 3:77-92.

35. Steinbrecher, U.P., Witztum, J.L., Parthasarathy, S., and Steinberg, D. 1987. Decrease in reactive amino groups during oxidation or endothelial cell modification of LDL. Correlation with changes in receptor-mediated catabolism. Arteriosclerosis. 7:135-143.

36. Zhang, H., Yang, Y., and Steinbrecher, U.P. 1993. Structural requirements for the binding of modified proteins to the scavenger receptor of macrophages. J. Biol. Chem. 268:5535-5542.

37. Hoppe, G., O’Neil, J., Sayre, L.M., and Hoff, H.F. 1997. Non-conventional modification of low density lipoproteins: chemical models for mar- cophage recognition of oxidized LDL. Biochim. Biophys. Acta. 1362:103-108.

38. Palinski, W., Miller, E., and Witztum, L.J. 1995. Immunization of LDL receptor-deficient rabbits with homologous malondialdehyde-modified LDL reduces atherogenesis. Proc. Natl. Acad. Sci. USA. 92:821-825.

39. Nilsson, J., et al. 1997. Immunization with homologous oxidized low density lipoprotein reduces neointimal formation after balloon injury in hypercholesterolemic rabbits. J. Am. Coll. Cardiol. 30:1886-1891.

40. Ameli, S., et al. 1996. Effect of immunization with homologous LDL and oxidized LDL on early atherosclerosis in hypercholesterolemic rabbits. Arterioscler. Thromb. Vasc. Biol. 16:1074-1079.

41. George, J., et al. 1998. Hyperimmunization of apo-E-deficient mice with homologous malondialdehyde low-density lipoprotein suppresses early atherogenesis. Atherosclerosis. 138:147-152.

42. Freigang, S., Hörkkö, S., Miller, E., Witztum, J.L., and Palinski, W. 1998. Immunization of LDL receptor-deficient mice with homologous malondialdehyde-modified and native LDL reduces progression of atherosclerosis by mechanisms other than the induction of high titers of antibodies to oxidative neoepitopes. Arterioscler. Thromb. Vasc. Biol. In press.

43. Salonen, J.T., et al. 1992. Autoantibody against oxidised LDL and progression of carotid atherosclerosis. Lancet. 339:883-887. 